\title{
Vegetative Compatibility Groups of Fusarium oxysporum f. sp. lactucae from Lettuce
}

Matias Pasquali, Flavia Dematheis, Giovanna Gilardi, Maria Lodovica Gullino, and Angelo Garibaldi, Di.Va.P.R.A. and Centre of Competence for the Innovation in the Agro-Environmental Field (AGROINNOVA), via Leonardo da Vinci, 4410095 Grugliasco (TO), Italy

\begin{abstract}
Pasquali, M., Dematheis, F., Gilardi, G., Gullino, M. L., and Garibaldi, A. 2005. Vegetative compatibility groups of Fusarium oxysporum f. sp. lactucae from lettuce. Plant Dis. 89:237-240.

Fusarium oxysporum f. sp. lactucae, the causal agent of Fusarium wilt of lettuce, has been reported in three continents in the last 10 years. Forty-seven isolates obtained from infected plants and seed in Italy, the United States, Japan, and Taiwan were evaluated for pathogenicity and vegetative compatibility. Chlorate-resistant, nitrate-nonutilizing mutants were used to determine genetic relatedness among isolates from different locations. Using the vegetative compatibility group (VCG) approach, all Italian and American isolates, type 2 Taiwanese isolates, and a Japanese race 1 were assigned to the major VCG 0300. Taiwanese isolates type 1 were assigned to VCG 0301 . The hypothesis that propagules of Fusarium oxysporum f. sp. lactucae that caused epidemics on lettuce in 2001-02 in Italian fields might have spread via import and use of contaminated seeds is discussed.
\end{abstract}

Additional keywords: Lactuca sativa
Lettuce (Lactuca sativa L.) belongs to the Compositae (Asteraceae) family. It is cultivated widely in the world (Fig. 1) and seven horticultural types have been defined: crisphead, butterhead, romaine (or cos), leaf, stem, latin, and oilseed (21). Despite its low nutritional value and lack of diversity in food preparation, lettuce is very important as a main component of salads and ranks fourth (1) in vegetable popularity. It is considered a "daily vegetable" by $90 \%$ of Italian consumers (1) and the sector is attracting lots of investments because it is a very common vegetable for processing and selling in single-family meal packages.

In the last 30 years, Fusarium oxysporum Schlechtend. pathogenic isolates on lettuce, causal agents of Fusarium wilt on lettuce, have been reported in many countries (Japan, the United States, Taiwan, Iran, an Italy).

The disease first was reported more than 30 years ago by Matuo and Motohashi (16) in Japan, where it was defined as root rot of lettuce. More recently, new centers of the disease have been reported in the United States, in 1990-91 in California, where $F$. oxysporum f. sp lactucum was

Corresponding author: M. Pasquali

E-mail: matias.pasquali@unito.it

The work was supported by Lumbardy Region and by European Project “STOVE” QLRT-2001-02239.

Accepted for publication 28 September 2004.

DOI: 10.1094/PD-89-0237

(C) 2005 The American Phytopathological Society described (11) and where $70 \%$ of American lettuce is produced, and in Arizona (15). A Fusarium disease described as root rot also was found in Taiwan (10), in Iran (17), and in different Japanese regions, including Nagano Prefecture in 1995 (4) and Hokkaido in 1997 (22). Taiwanese isolates were divided into two different morphological types (10), and the Japanese isolates used in this study belong to two different races. A third race recently has been identified (5). American and Italian isolates proved to behave similarly in a pathogenicity tests (8).

Previous studies $(5,9)$ suggested that $F$. oxysporum f. sp. lactucum and f. sp. lactu- cae are similar; therefore, we will use the latter name to address the isolates pathogenic on lettuce obtained in Italy. In this work, both types of isolates have been included.

Epidemics of Fusarium wilt on lettuce in Northern Italy first were reported in 2001 (6); this was the first report in Europe. The incidence of wilted lettuce plants in different fields varied between 20 and $60 \%$ after 2 years of continuous cropping (6). In order to investigate the origin of the isolates collected in Italy and eventually to define genetic relatedness among isolates from different geographical areas, the vegetative compatibility group (VCG) approach $(3,20)$ was taken. VCG is a technique to classify races, nonpathogenic, and pathogenic populations of $F$. oxysporum (13).

The aim of the study was to (i) evaluate the level of genetic variability of the epidemics in Italy, (ii) add proof to the hypothesis made by Garibaldi et al. (7) that the epidemics may have spread by contaminated seed, and (iii) confront the VCG of the Italian isolates with representatives of the pathogen in the forma specialis lactucae and lactucum worldwide. In particular, isolates from Italy, the United States, Japan, and Taiwan were used in this study.

\section{MATERIALS AND METHODS}

Isolate collection. All the isolates used in the study are listed in Table 1 . The ma-

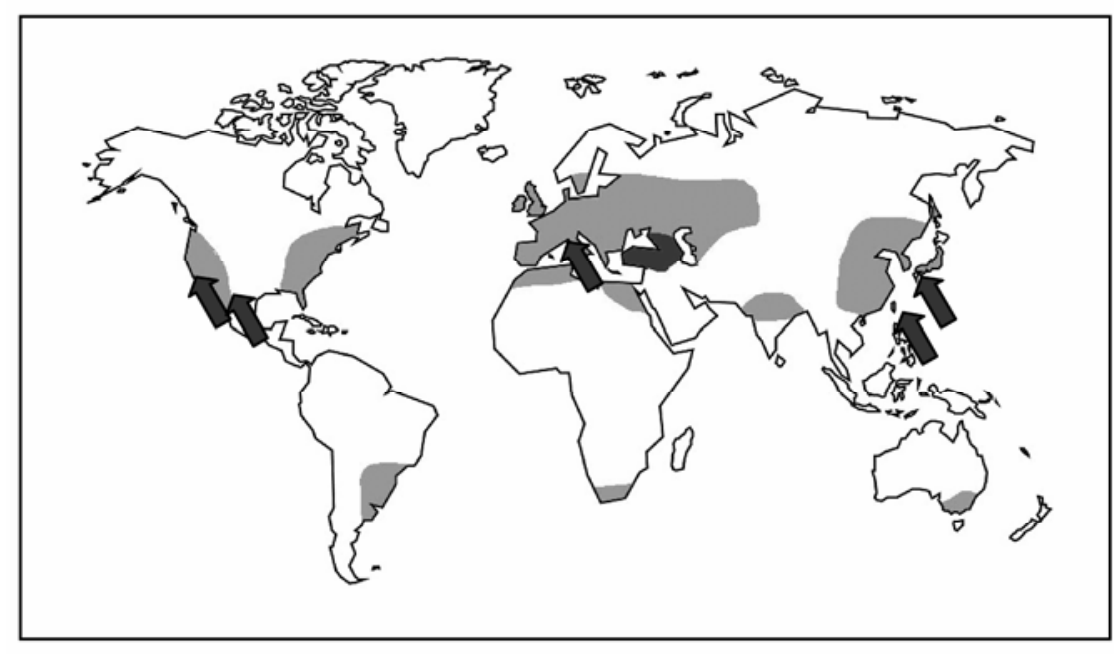

Fig. 1. World distribution of lettuce fields (gray) and genetic center of origin of Lactuca sativa (dark gray). Dark-gray arrows indicate the origin of the isolates used in this study. Map kindly provided by Max Planck Institute for Plant Breeding Research, Koln, Germany. 
jority of the isolates originated from affected fields, plants, and seed in Italy in the years 2001 and 2002, when the disease suddenly appeared in Europe. The center of disease is the Bergamo area in the Lumbardy region. Sampling was conducted by isolating infected plants from different farms in this area. All the Italian samples were collected in different farms. These isolates were obtained by Garibaldi et al. (6) by plating stems and roots of symptomatic lettuce plants following isolation procedure described in Pasquali et al. (18); the isolates were then stored on potato dextrose agar (PDA) at $7^{\circ} \mathrm{C}$. Japanese isolates SB1-1 (race 1) and F-9501 (race 2) were kindly provided by Dr. M. Fujinaga. Taiwanese isolates FOL 10 (type 1), FOL 11 (type 2), FOL 18 (type 2), and FOL 40 (type 1) were kindly provided by Dr. J. H. Huang. American isolates with JCP code were kindly provided by Dr. M. E. Matheron, and isolates with AZ code were kindly provided by Dr. J. Petersen. The reference isolate ATCC 76616 (representative of $F$. oxysporum f. sp. lactucum) was obtained from American Type Culture Collection.

Single-spore cultures were prepared for each strain and used for the following experiments.

Pathogenicity test. All the isolates listed in Table 1 were tested for their pathogenicity. Five 15-day-old lettuce plants, cv. Romano Odessa, highly susceptible to Fusarium wilt (7), were inoculated after transplanting. Plants were grown at $25^{\circ} \mathrm{C}$ from commercial seed (Sluis and Groot, Inc., Enkhuizen, The Netherlands). Each conidial suspension $(5 \mathrm{ml})$ was applied at the root level of plants. A control of 10 plants was prepared using sterile

Table 1. Isolates of Fusarium oxysporum from lettuce listed by isolate, forma specialis, origin, pathogenicity on lettuce cv. Romano Odessa, and vegetative compatibility group (VCG)

\begin{tabular}{|c|c|c|c|c|}
\hline Isolate code & Forma specialis & Geographic origin & Pathogenicity $^{\mathrm{a}}$ & $V_{C G} \mathbf{b}$ \\
\hline $1 \mathrm{~A}$ & lactucae & Italy & + & 0300 \\
\hline $2 \mathrm{~A}$ & lactucae & Italy & + & 0300 \\
\hline $3 \mathrm{~A}$ & lactucae & Italy & + & 0300 \\
\hline $4 \mathrm{~A}$ & lactucae & Italy & + & 0300 \\
\hline $5 \mathrm{~A}$ & lactucae & Italy & + & 0300 \\
\hline 1 & lactucae & Italy & + & 0300 \\
\hline 2 & lactucae & Italy & + & 0300 \\
\hline 3 & lactucae & Italy & + & 0300 \\
\hline 4 & lactucae & Italy & + & 0300 \\
\hline 5 & lactucae & Italy & + & 0300 \\
\hline 6 & lactucae & Italy & + & 0300 \\
\hline 7 & lactucae & Italy & + & 0300 \\
\hline $8 \mathrm{~A}$ & lactucae & Italy & + & 0300 \\
\hline $8 \mathrm{~B}$ & lactucae & Italy & + & 0300 \\
\hline $8 \mathrm{C}$ & lactucae & Italy & + & 0300 \\
\hline $10 \mathrm{~A}$ & lactucae & Italy & + & 0300 \\
\hline $14 \mathrm{~A}$ & lactucae & Italy & + & 0300 \\
\hline $15 \mathrm{~A}$ & lactucae & Italy & + & 0300 \\
\hline $15 \mathrm{C}$ & lactucae & Italy & + & 0300 \\
\hline $9 \mathrm{~A}$ & lactucae & Italy & + & 0300 \\
\hline $9 \mathrm{C}$ & lactucae & Italy & + & 0300 \\
\hline $9 \mathrm{D}$ & lactucae & Italy & + & 0300 \\
\hline $11 \mathrm{~A}$ & lactucae & Italy & + & 0300 \\
\hline $11 \mathrm{~B}$ & lactucae & Italy & + & 0300 \\
\hline $11 \mathrm{C}$ & lactucae & Italy & + & 0300 \\
\hline $11 \mathrm{D}$ & lactucae & Italy & + & 0300 \\
\hline $17 \mathrm{~A}$ & lactucae & Italy & + & 0300 \\
\hline $17 \mathrm{~B}$ & lactucae & Italy & + & 0300 \\
\hline 1 II (from seed) & lactucae & Italy & + & 0300 \\
\hline 7 E (from seed) & lactucae & Italy & + & 0300 \\
\hline JCP 0024 & lactucae & Arizona & + & 0300 \\
\hline ATCC 76616 & lactucum & California & + & 0300 \\
\hline JCP 0043 & lactucum & California & + & 0300 \\
\hline JCP 0089 & lactucum & California & + & 0300 \\
\hline JCP 0163 & lactucum & California & + & 0300 \\
\hline $\mathrm{Az}-01$ & lactucum & California & + & 0300 \\
\hline AZ-03 & lactucum & California & + & 0300 \\
\hline AZ-05 & lactucum & California & + & 0300 \\
\hline SB1-1 (race 1) & lactucae & Japan & + & 0300 \\
\hline 9501 (race 2) & lactucae & Japan & + & 030-HSI \\
\hline FOL 11 (type 2) & lactucum & Taiwan & + & 0300 \\
\hline FOL 18 (type 2 ) & lactucum & Taiwan & + & 0300 \\
\hline FOL 10 (type 1$)$ & lactucum & Taiwan & + & 0301 \\
\hline FOL 40 (type 1$)$ & lactucum & Taiwan & + & 0301 \\
\hline 1 I (from seed) & Unknown & Italy & - & A \\
\hline 7 I (from seed) & Unknown & Italy & - & A \\
\hline 6 II (from seed) & Unknown & Italy & - & $\mathrm{B}$ \\
\hline
\end{tabular}

\footnotetext{
a At 30 days since inoculation, $+=$ dead plants and $-=$ healthy plants (no symptoms).
}

${ }^{b}$ HIS = heterokaryon self-incompatible. water. The inoculum was prepared by growing the fungus in 250-ml Erlenmeyer flasks (Bibby Sterilin Ltd., Stone, UK) containing $100 \mathrm{ml}$ of potato dextrose broth (concentration, 24 g/liter; Difco Laboratories, Detroit) and yeast extract (concentration, $5 \mathrm{~g} /$ liter; Difco Laboratories) with shaking (acceleration, $0.1 \mathrm{~m}^{2} / \mathrm{s}$ ) at $25^{\circ} \mathrm{C}$ under constant light. After 6 days, fungal cultures were aseptically filtered through four layers of cheesecloth and conidia were brought to a final density of $1 \times 10^{6}$ spores/ml in Ringer solution (Difco Laboratories), estimating the concentration of the solution by counting with a hemocytomer.

Plastic pots (one plant per pot, 1-liter capacity, $12-\mathrm{cm}$ side) were filled with a steamed mixture containing 60:20:20 ( vol/vol/vol) of peat:compost broadleaf bark:clay. The pots were watered daily and kept in a room at controlled temperature $\left(25^{\circ} \mathrm{C}\right.$; relative humidity, 50 to $90 \%$; daily light conditions, 50 to $60 \mathrm{kl} / \mathrm{m}^{2}$ ). Disease progress was measured every 5 days, from 30 days after inoculation and transplant, using a scale of symptoms from 0 to 5 , where $0=$ no symptoms; $1=$ slight stunting, no yellowing; $2=$ minor wilt and stunting, yellowing (10 to $30 \%$ leaves); $3=$ moderate wilt, stunted, yellowing (30 to $60 \%$ leaves); $4=$ severe wilt, stunted, yellowing (60 to $90 \%$ leaves); and $5=$ dead (no green leaves). Plants were evaluated and + was assigned when all five plants were completely dead and - when all the plants showed no symptoms (Table 1). The test was repeated once.

Recovery of nitrate-nonutilizing mutants and complementation tests. Each isolate was grown on PDA for 4 days at $25^{\circ} \mathrm{C}$. Then, four small fragments of mycelium per strain were transferred to the chlorate-amended media potato dextrose with chlorate (PDC; five plates per isolate) and minimal medium (MM) with chlorate (MMC; five plates per isolate) as described by Correll et al. (3). At least 30 chlorateresistant sectors per isolate were recovered after 6 to 10 days of incubation at $27^{\circ} \mathrm{C}$ and transferred for 3 days on MM, a sucrose-salt medium that contains nitrate as the sole nitrogen source (3). Mutants showing a thin growth on MM were considered nitrate-nonutilizing (nit) mutants. They were grown on hypoxantine media (HMM) for 3 days to identify mutants with Nit M phenotype that generated aerial mycelium. The discrimination between nit 1 and nit 3 mutants was not carried out.

Self-compatibility of the isolates was tested by paring on each MM plate, in all possible combinations, all mutants from the same isolate. The period of incubation was 2 weeks at a temperature of $27^{\circ} \mathrm{C}$. Complementarity was defined when an aerial mycelium grew at the intersection of two mycelia. When complementary mutants were not obtained, two more trials for obtaining mutants were performed using 2 
and 3\% chlorate PDC and MMC substrates. If no compatible mutants were observed on MM, the isolate was defined as self-incompatible.

Two complementary mutants for each isolate were selected (usually two different Nit $\mathrm{M}$ or one Nit $\mathrm{M}$ and one nit1/nit3) and paired on $\mathrm{MM}$ in all possible combinations. Heterokaryon formation was evident (Fig. 2) from the robust mycelial growth at the interface of the two developing colonies (3). Complementation was assessed after 5, 10, and 15 days. VCG assignation to the same group was decided when nit mutants from different isolates produced robust heterokaryons with each other before 10 days.

\section{RESULTS}

Pathogenicity test. All the isolates listed in Table 1 were tested for pathogenicity on lettuce cv. Romano Odessa. First symptoms appeared at the second week after inoculation. No significant difference was observed in the timing and kind of symptoms among isolates from Italy, the United States, Japan, and Taiwan. The progress of the disease was identical for all the virulent isolates (after 15 days, the pathogenic isolates all rated 3 to 4 on the scale of symptoms). All the pathogenic isolates caused the death of lettuce plants in less than 30 days. All the isolates obtained from diseased plants were highly pathogenic, thus confirming their designation as forma specialis lactucae. Also, two seed isolates (7E and 1II) were pathogenic, confirming results obtained by Garibaldi et al. (6). Three of the five isolates from seed were not pathogenic on lettuce. Results of pathogenicity are summarized in Table 1, distinguishing pathogenic isolates $(+)$ from nonpathogenic isolates (-).

Vegetative compatibility tests. The number of Nit $M$ mutants obtained from both chlorate substrates was evaluated to compare the efficacy of different media in the production of nit mutants useful for VCG analysis. In agreement with previous reports (19,23), many Nit M mutants were produced on MMC. PDC generated a higher frequency of chlorate-resistant mutants not useful for VCG analysis. In all, 120 mutants (15 Nit M) were obtained from isolate F-9501 and crossed in all possible combinations, but no complementation was observed; therefore, this isolate was considered self-incompatible. Most isolates produced complementary nit mutants at $1.5 \%$ chlorate. Complementary mutants of isolates FOL 18, SB-1, FOL 11, and $5 \mathrm{~A}$ were obtained at $3 \%$ chlorate.

Based on the complementation pattern, all the Italian isolates pathogenic on lettuce were assigned to VCG 0300 (12). Compatibility with Italian isolates also was verified for the eight American isolates. Isolates FOL 11 and FOL 18, belonging to type 2 from Taiwan, and isolate SB-1 race 1 from Japan also grouped in VCG 0300.
The type 2 isolates from Taiwan (FOL 10 and FOL 40) belong to a different VCG, designated VCG 0301. Isolates obtained from Italian seed stocks that were pathogenic on lettuce (7E and 1 II) complemented with VCG 0300 representatives. On the other hand, isolates 7I and 1I grouped together but, along with isolate 6II, were not pathogenic on lettuce, nor were these three isolates compatible with VCGs mentioned above.

\section{DISCUSSION}

The recent spread of the Fusarium wilt disease on lettuce worldwide has captured attention because of the high economic importance of the crop. In Italy alone, 22,000 ha of lettuce are grown every year (3,000 ha in greenhouses). The isolates belonging to forma specialis lactucae studied here belong to two different VCGs, whereas nonpathogenic isolates obtained from lettuce seed are not compatible with these VCGs.

In particular, all the isolates that caused an epidemic in Italy belong to a single VCG. Following Kistler et al. (14) and Katan and DiPrimo (12), they were assigned to VCG 0300. These results showed that all the isolates that caused epidemics in Italian lettuce fields in 2001 and 2002 have a common origin, belonging to the same VCG shared by American, Japanese, and Taiwanese isolates. Furthermore, isolates from California and Arizona probably have a common origin. Thus, the fact that, with the exception of type 1 isolates from Taiwan and the self-incompatibility problem of isolate F-9501 from Japan, all isolates pathogenic on lettuce used in this

study belong to VCG 0300 suggests the spread of a common clone in different countries, probably by propagation material. Isolation from two different stocks of seed of two isolates belonging to VCG 0300 used in Italy further suggests that the pathogen might have been introduced by contaminated seed (7). These results may be useful for Italian growers: an economic and valuable approach would be to choose resistant cultivars evaluated in the United States and Japan while further studies on the pathogen are carried out in Italy.

VCG comparison confirmed the similarity of isolates identified as $F$. oxysporum f. sp. lactucae (Italian and Japanese) and $F$. oxysporum f. sp. lactucum (American and Taiwanese) and integrated the results obtained by others $(5,8,9)$. Therefore, we adopted the name $F$. oxysporum f. sp. lactucae (16) for all the isolates in VCG 030-

The presence of a second VCG will be investigated further with molecular analysis in order to examine whether the type 1 strain from Taiwan, belonging to VCG 0301, is the effect of divergent evolution within a single population, or if type 1 has originated from a different source. Pathogenicity results on cv. Romano Odessa did not reveal any difference to VCG 0300; therefore, the use of many cultivars may explain whether pathogenicity behavior may be used to distinguish the two populations.

Fujinaga et al. (4) described two races that were represented here by isolates F9501 and SB1-1. Of these, race 1 belongs to the cosmopolitan VCG, whereas the race 2 isolate (F-9501) was self-incompati-

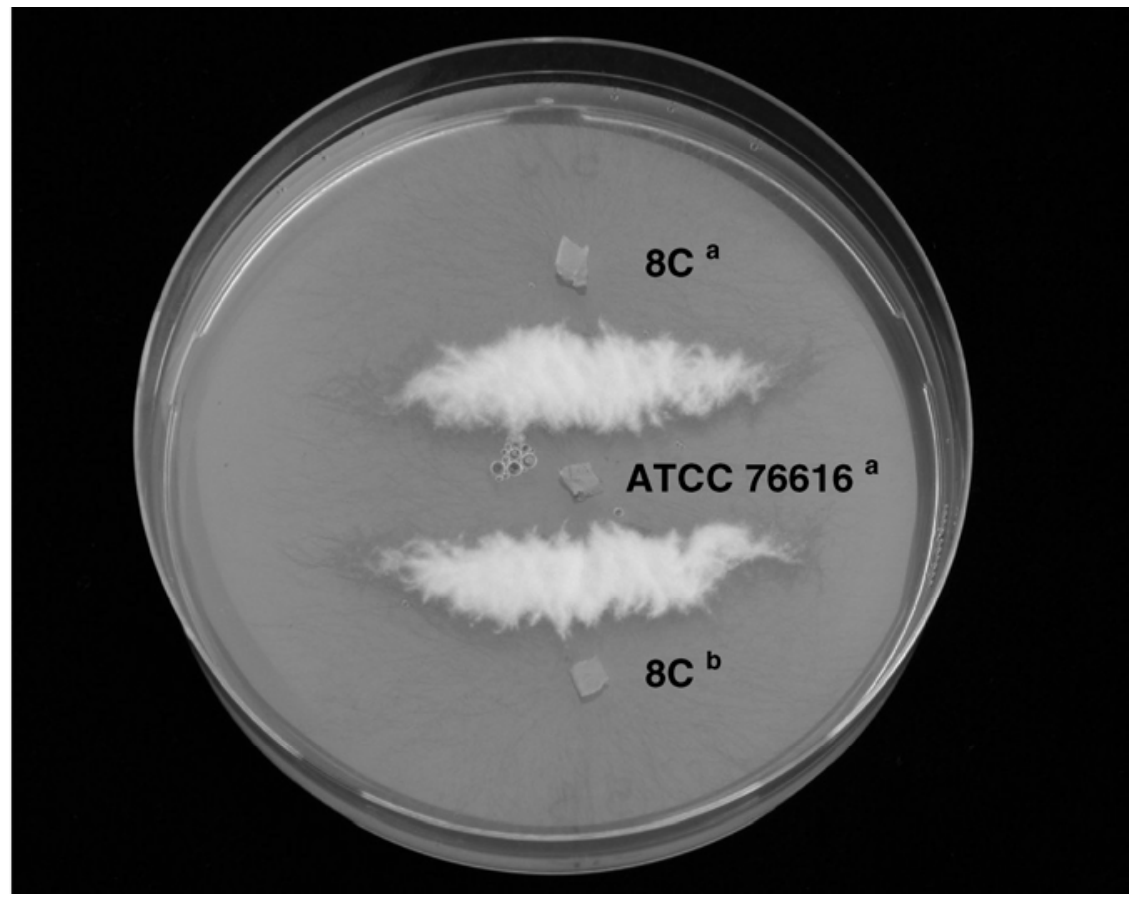

Fig. 2. Complementation test on minimal medium substrate after 10 days of growth of chlorate-resistant mutants obtained from the American isolate ATCC76616 and the Italian isolate 8C; $a=\mathrm{Nit}$ M and $\mathrm{b}=$ nit $1-3$. 
ble. A third race was described in 2003 (5) but no representatives of race 3 were available at the beginning of our study. Future studies on VCG will certainly need to analyze more deeply the Japanese isolates that were reported in different regions of Japan. Japanese isolates assume a very important role because they may be the origin of the disease that was first identified in 1967. Acquiring knowledge of the development of Japanese races may be useful in the choice of genotypes to be used by American and Italian breeders.

In this study, analysis of VCGs does not unravel the immediate origin of inoculum responsible for epidemics in Italy, because American, Taiwanese, and Japanese isolates all belong to the same VCG. Further studies using specific markers are needed to understand the precise geographic origin of the epidemics in Italy.

Because three races have been described in Japanese isolates, and cultivar specialization has been reported in Italy (8), the United States (9), and Japan (24), our laboratory is investigating the level of genotypic variability among isolates to possibly identify races or pathogenicity behavior. Certainly the fact that a common population is widespread may facilitate the adoption of a molecular approach for the identification of the pathogen; in fact, the use of molecular methods for detection of the pathogen on seed (2), such as specific polymerase chain reaction, may improve the management of epidemics, reducing seed transmission of the disease by seed certification.

\section{ACKNOWLEDGMENTS}

We thank M. Ferrari for VCG technical help, J. Griffin for English proofreading, and the anonymous referees. The work was supported by Lumbardy Region and by European Project "STOVE" QLRT-2001-02239.

\section{LITERATURE CITED}

1. Borghi, S. 2004. Consumatori tranquilli con Bonduelle. Speciale Insalate, Suppl. Terra Vita 10:17-19. (In Italian.)

2. Chiocchetti, A., Sciandone, L., Durando, F., Garibaldi, A., and Migheli, Q. 2001. PCR detection of Fusarium oxysporum f. sp. basilici on basil. Plant Dis. 85:607-611.

3. Correll, J. C., Klittich, C. J. R., and Leslie, J. F. 1987. Nitrate non-utilizing mutants of Fusarium oxysporum and their use in vegetative compatibility tests. Phytopathology 77:16401646.

4. Fujinaga, M., Ogiso, H., Tsuchiya, N., and Saito, H. 2001. Physiological specialization of Fusarium oxysporum f. sp. lactucae, a causal organism of Fusarium root rot of crisp lettuce in Japan. J. Gen. Plant Pathol. 67:205-206.

5. Fujinaga, M., Ogiso, H., Tuchiya, N., Saito, H., Yamanaka, S., Nozue, M., and Kojima M. 2003. Race 3, a new race of Fusarium oxysporum f. sp. lactucae determined by a differential system with commercial cultivars. J. Gen. Plant Pathol. 69:23-28.

6. Garibaldi, A., Gilardi, G., and Gullino, M. L. 2002. First report of Fusarium oxysporum on lettuce in Europe. Plant Dis. 86:1052.

7. Garibaldi, A., Gilardi, G., and Gullino, M. L 2004. Seed transmission of Fusarium oxysporum f. sp. lactucae. Phytoparasitica 32:61-65.

8. Garibaldi, A., Gilardi, G., and Gullino, M. L. 2004. Varietal resistance of lettuce to Fusarium oxysporum f. sp. lactucae. Crop Prot. 23:845-851.

9. Grube, R. C., Ryder, E. J., Koike, S. T., McCreight, J. D., and Wintermantel, W. M. 2003. Breeding for resistance to new and emerging lettuce diseases in California. Pages 25-30 in: Proc. Eucarpia Leafy Vegetables Conf. 2003, Noordwijkerhout, The Netherlands.

10. Huang J. H., and Lo, C. T. 1998. Wilt of lettuce caused by Fusarium oxysporum in Taiwan. Plant Pathol. Bull. 7:150-153.

11. Hubbard, J. C., and Gerik, J. C. 1993. A new wilt disease of lettuce incited by Fusarium oxysporum f. sp. lactucum forma specialis nov. Plant Dis. 77:740-754.

12. Katan, T. 1999. Current status of vegetative compatibility groups in Fusarium oxysporum. Phytoparasitica 27:51-64.

13. Katan, T., and Katan, J. 1999. Vegetative Compatibility grouping in Fusarium oxysporum $\mathrm{f}$. sp. radicis lycopersici from the UK, the Netherlands, Belgium and France. Plant Pathol. 48:541-549.

14. Kistler, H. C., Alabouvette, C., Baayen, R. P., Bentley, S., Brayford, D., Coddington, A., Correll, J., Daboussi, M. J., Elias, K., Fernandez, D., Gordon, T. R., Katan, T., Kim, H. G., Leslie, J. F., Martyn, R. D., Migheli, Q., Moore, N. Y., O'Donnell, K., Ploetz, R. C., Rutherford, M. A., Summerell, B., Waalwijk, C., and Woo, S. 1998. Systematic numbering of vegetative compatibility groups in the plant pathogenic fungus Fusarium oxysporum. Phytopathology 88:30-32.

15. Matheron, M. E., and Koike, S. T. 2003. First report of Fusarium wilt of lettuce caused by Fusarium oxysporum f. sp. lactucae in Arizona. Plant Dis. 87:1265.

16. Matuo, T., and Motohashi, S. 1967. On Fusarium oxysporum f. sp. lactucae n.f. causing root rot of lettuce. Trans. Mycol. Soc. Jpn. 8:13-15.

17. Millani, M. J., Erebarian, H. R., and Alizadeh, A. 1999. Occurrence of Fusarium wilt of lettuce in Shahr-Ray, Varamin and Karaj areas. Iran. J. Plant Pathol. 35:121.

18. Pasquali, M., Acquadro, A., Balmas, V., Migheli, Q., Gullino, M. L., and Garibaldi, A. 2003. RAPD characterization of Fusarium oxysporum isolates pathogenic on Argyranthemum frutescens L. J. Phytopathol. 151:30-35.

19. Pasquali, M., Marena, L., Gullino, M. L., and Garibaldi, A. 2004. Vegetative compatibility grouping of Fusarium wilt pathogen of Paris daisy (Argyranthemum frutescens L.). J. Phytopathol. 152:257-259.

20. Puhalla, J. E. 1985. Classification of strains of Fusarium oxysporum on the basis of vegetative compatibility. Can. J. Bot. 63:179-183.

21. Ryder, R. J. 1998. Lettuce, Endive and Chicory. CABI Pubblishing, Wallingford, UK.

22. Simizu, M. 1998. Occurrence of root rot of lettuce caused by Fusarium oxysporum f. sp. lactucae in Hokkaido. Ann. Rep. Soc. Plant Prot. N. Jpn. 49:51-53.

23. Swift, C. E., Wickliffe, E. R., and Schwartz, H. F. 2002. Vegetative compatibility groups of Fusarium oxysporum f. sp. cepae from onion in Colorado. Plant Dis. 86:606-610.

24. Yamauchi, N., Horiuchi, S., and Satou, M. 2001. Pathogenicity groups in Fusarium oxysporum f. sp. lactucae on horticultural types of lettuce cultivars. J. Gen. Plant Pathol. 67:288-290. 